\title{
Identification of various droughts Prone talukas for Dahod district of Gujarat
}

\section{SHARAD KUMAR NAMDEV AND MUNISH KUMAR PANDEY}

Received : 07.03.2017; Revised : 05.07.2017; Accepted : 19.07.2017

See end of the Paper for authors' affiliation Correspondence to :

SHARAD KUMAR NAMDEV School of Agriculture, ITM University, GWALIOR (M.P.) INDIA

Email : sharadsftr@gmail.com
- ABSTRACT : Drought is one of the most serious problems arising for human societies and ecosystems from climate variability. Although its impact does not come through sudden events, such as flood and storms, drought is the world's costliest natural disaster, causing an average \$6$\$ 8$ billion in global damages annually and collectively affecting more people than any other form of natural disaster (Wilhite, 2000). The National Commission on Agriculture (MOA, 1976) identified 74 drought prone districts which all are located 13 states of India and Gujarat is one of the most drought prone areas of India in which, eleven districts of the state are in arid regions including Dahod region one of most backward district; agriculture based livelihood income and experienced drought problems many times throughout the years due to delayed in rainfall. Therefore, study was carried out to determine hydrological and agriculture panoramas of drought in the Dahod district includes 7 Talukas. It was found that annual rainfall in Dahod district varies between 690 $\mathrm{mm}$ at Garwada to $847 \mathrm{~mm}$ at limkheda with the average annual rainfall of $833 \mathrm{~mm}$ and average drought frequency in Dahod district varies between 1 in 4 years at Jalod, Limkheda 1 in 3 years, Devgarh 1 in 5 years, Garbada 1 in 3 years, Dhanpur 1 in 3 years, and 1 in 3 years at Fatepura. The relative departure index (RDI) was observed for various Talukas in which, Dahod district was recorded frequent drought prone taluka and considered for taking up drought mitigation activities. The standardized precipitation index (SPI) was analysed between the year of mid 1999-2003 taluka was suffered from moderate and severe drought conditions whereas, between the years of mid 1993 to mid 1999 meteorological condition was normal.

- KEY WORDS : Drought prone, Identification, Annual rainfall, Departure analysis, Drought frequency, Drought severity

- HOW TO CITE THIS PAPER : Namdev, Sharad Kumar and Pandey, Munish Kumar (2017). Identification of various droughts Prone talukas for Dahod district of Gujarat. Internat. J. Agric. Engg., 10(2) : 253-259, DOI: 10.15740/HAS/IJAE/10.2/253-259. 